\title{
Research on the Management Methods of Youth Campus Football Teaching
}

\author{
Chen Wang ${ }^{1, *}$ \\ ${ }^{1} X i$ 'an FanYi University, Xi'an, Shaanxi, China \\ *Corresponding author. Email: 764715840@qq.com

\begin{abstract}
This article takes Shaanxi Province as an example to analyze and study the current situation and management methods of youth campus football teaching. Through research, questionnaire survey and discussion on teaching management, it is found that the current development of campus football and the existing problems in football teaching mainly include: deviation of ideology, limitation of teaching staff, simple teaching methods and insufficient teaching monitoring methods, which are the key reasons that restrict the development of football teaching. Through this article, the research and development of football teaching reform and innovation are analyzed, and scientific and reasonable suggestions are put forward for the development of campus football, returning to the origin of campus football, broadening the development of campus football, and taking advantage of off-campus resources.
\end{abstract}

Keywords: football campus, teaching curriculum, teaching development, teaching management

\section{INTRODUCTION}

The Ministry of Education has formulated the "National Youth School Football Teaching Guide (Trial)" (hereinafter referred to as the "Guide"). In order to thoroughly implement the spirit of the documents of the General Office of the Ministry of Education, in accordance with the requirements of accelerating the development and popularization of campus football, it is necessary to further promote the school's sports work and improve the physical and mental health of students, promote the all-round development, healthy development and harmonious development of students, improve students' sports quality and sports competition level, and ensure the standardized and orderly development of campus football teaching. However, in the process of practice, physical education teachers are faced with operational problems. How to realize the educational value of campus football in the process of implementing the "Guide" still lacks effective ways.

\section{RESEARCH OBJECTS}

This article faces the teaching methods of football courses in elementary and middle schools as the objects, and conducts research.

\section{RESEARCH METHODS}

\section{A. Literature data method}

In this paper, by consulting a large number of *Project: Project No.: 2019074. domestic and foreign documents, it carries out research and discussion based on relevant youth football teaching methods.

\section{B. Questionnaire surveys and expert interviews}

Questionnaire surveys and expert discussions were conducted on 10 primary and secondary schools in the region. The problems and deficiencies found in the questionnaire were counted and discussed with experts.

\section{Observation method}

It is to visit 10 schools to study and observe youth football teaching classrooms, and record teaching problems and deficiencies, and summarize excellent and good teaching methods.

\section{RESEARCH CONTENT}

As China has successively promulgated many important documents on football reform in recent years, people have deeply understood the spirit from them. Combined with the needs of football reform and development work, people have been able to explore how to improve the development of youth campus football sports culture. Subsequently, the "National Youth Campus Football Activities Implementation Plan" has also been carried out. So far, the Chinese state and national sports related departments have successively issued a number of documents, which are all about how to improve and develop the spiritual requirements of the documents of the youth campus football culture in China. How to learn in the field to 
improve the course of youth campus football culture to professional football culture, promote a new level of reform, and promote youth football has also begun to appear a substantial development trend.

\section{A. Organizing}

1) Attaching great importance to sports and students' physical health, and carrying out sports courses and campus football in accordance with the sports and health curriculum standards and related regulations: The school incorporates football into the learning development plan, into the annual learning plan and semester plan, and into the school's usual agenda.

2) Improving the working mechanism: It is necessary to establish a leadership group under the leadership of the principal, the school's academic affairs office, student office, sports team and other relevant departments cooperate to participate in the campus football work to specifically guide the development of campus football work.

3) Establishing perfect rules and regulations: The school formulates regulations and work systems for campus football work, enrollment, teaching management, training and competition, sports safety, teacher training, inspection and supervision, etc., and constantly improves them. The specific work is arranged by the Academic Affairs Office.

\section{B. Teachers guarantee}

The first is to strengthen the physical education teacher resources. It is necessary to equip with enough physical education teachers to meet the needs of teaching work, and at least one football professional physical education teacher. Every year, physical education teachers can be provided with opportunities to participate in professional training. The school should regularly conduct physical education research and continuously improve the teaching skills of physical education teachers.

The second is that football teaching and football training activities carried out by physical education teachers can be included in the workload. And it can ensure that physical education teachers enjoy the same treatment in terms of evaluation, salary, and job evaluation.

The third is that the venue facilities and equipment should be basically up to national standards, meet the needs of sports work, and constantly supplemented. And the school also should build a football field suitable for school conditions and sufficient equipment for basic football training competitions. At the same time, the school should actively purchase football and various football-related equipment, and make football training facilities be in place.

The forth is to set up a special fund for sports work and include it in the school's annual budget. In principle, the special fund for sports is not less than $10 \%$ to ensure the normal development of sports and campus football. On the basis of implementing school liability insurance for students, a new sports accident injury insurance needs to be purchased for students.

\section{Teaching management}

First, the educational background and mandarin of physical education teachers must meet the requirements of the superior department.

Second, the concept of physical education is to deepen the reform of school physical education, insist on health-oriented, take football sports as a carrier of strengthening moral education and cultivating people, actively promote quality education, and promote the allround development and healthy growth of young people. In order to improve the level of football teaching and training, the school's library and reading room are open to all teachers, and books related to sports football are ordered for physical education teachers to encourage and support physical education teachers to visit and learn.

Third, the school should draw up a campus football teaching and research work plan each semester (including guiding ideology, work tasks and goals, specific measures and arrangements for teaching and research activities, compiling training and competition schedules, daily schedules and weekly calendars, and the sports safety precaution work plan, etc.), shall be submitted to the school for review and filing. At the end of the term, it is necessary to write a summary of campus football work, report on the implementation of the plan, and ensure time for physical education. Schools should strictly follow the establishment of a national campus football characteristic school to open classes and organize teaching activities, with more than two football lessons per week. The Office of Academic Affairs shall, in accordance with the requirements of the country, open all physical education classes to ensure that students have one hour of campus sports activities every day; the school physical education teachers should draw up a campus football teaching work plan at the beginning of the period.

Forth, it is to scientifically develop football curriculum resources, according to the national campus football teaching guidelines, develop and compile football teaching and training materials according to local conditions, implement football teaching and extracurricular activities suitable for each student's age characteristics, and make football teaching a school 
curriculum and extracurricular activities Important content.

Fifth, it is to create a campus football cultural atmosphere, often carry out campus sports cultural activities with football as the theme, establish an Internet-based campus football information platform, football activities, exchange work experience, and display characteristic results.

\section{Training and competition}

Firstly, it is necessary to cultivate students' active fighting spirit, enhance students' sense of competition, and discover and train high-cultural, high-quality, highlevel football talents. The school should take strengthening the construction of key football schools as an important task of the school, and pay attention to adopting various methods and methods, so that the school's football career can be greatly developed, and the students' football competition level can be continuously improved.

Secondly, according to the characteristics of students of different grades, it should actively carry out extracurricular activities football interest classes. Starting from cultivating students' interest in football, according to the characteristics of the first and second grade students, the school can organize them to practice dribbling and carry out shooting competitions. The third and fourth grade students have a certain foundation in football, and the school can organize them to carry out fun five-a-side or seven-a-side games, so that students can learn to pass and learn to communicate during the game. For the fifth and sixth grade students, they gradually develop a sense of cooperation with the children, and the school can organize various classes to form a football team to participate in the school league.

Thirdly, it is important to improve students' football competitive level and organize students to participate in competitions. The school forms a school-level football team among the fifth and sixth grade students. The football team insists on one hour of regular training every day and holds a contest every weekend.

Fourthly, in view of the effective significance of reform and innovation in the reform of youth physical education and the strong comprehensive performance of youth campus football, it can gradually form teaching mode and training method and mechanism, which can provide a better reference ability for school physical education for teenagers, inject fresh vitality, love sports, and advocate a healthy school culture for teenagers, and promote the development of China for national fitness and health.

\section{CONCLUSION}

Traditional teaching methods can no longer meet the needs of students, so more and more new instruments and equipment are introduced into the classroom, which increases students' curiosity and freshness, and at the same time increases students' enthusiasm for learning. Football teaching is no exception. With the passage of time, football teaching methods continue to develop and evolve, and a large number of new football teaching methods have emerged, which formed a modern football teaching method. Information feedback teaching method refers to relying on students' own practice and exploration, to obtain relevant football skills, and to communicate with others to obtain external evaluation and improve the infrastructure of physical education. The modern teaching process is essentially a process of interaction and mutual influence between teachers and students. A good teacher-student relationship can not only create a good teaching and learning environment, but also help improve teachers' teaching enthusiasm. In the improvement of football teaching methods, it is a must to pay attention to the students' dominant position, establish a "people-oriented" teaching concept, pay attention to the individual differences of students, formulate different teaching goals and teaching methods according to different needs, and use flexible and scientific teaching methods to enable students to master sports skills.

Young people's love for football has allowed them to learn and comprehend a series of good qualities and migrate to other fields to lay a solid foundation for the children's brilliant life.

First of all, it is necessary for people to strengthen the children's wonderful experience of playing football through praise and encouragement from home, society, campus leaders, teachers, coaches, and parents. The guiding behavior of youth and children's football coaches and teachers can influence and change children's football, which is a beautiful sport that takes root in children's hearts. Football is a lifelong sport that children learn and benefit from as they grow up. There are still many parents and teachers who stubbornly mistakenly believe that "children playing football will affect learning when they grow up" and do not approve of children playing football. The local and school's understanding of football is still somewhat superficial. When it comes to campus football or sports, it is considered to be a matter of a few sports specialties. Individuals with conservative thinking believe that "the characteristic of campus football is to build a school team to complete the document tasks given by the provincial and municipal leaders", and does not give full play to the core functions of campus sports. And people really want students to learn and master sports skills as the goal of physical education, and strictly guide the teaching work of campus football characteristic schools. Therefore, to do a good job in school sports is to strengthen the sports awareness and sports concept of the school education responsible 
person, and to better carry out the school sports work so as to guide the policy formulation to change the traditional school thinking. Only in this way can the development of youth campus football be truly improved on the basis of the great attention paid to the overall school sports work.

Secondly, in recent years, with the rapid development of football in China, and the introduction of the promotion policy advantages of youth campus football, the football talent pool has made great progress and changes, which reserved a large number of talents for the needs of campus and social institutions. This requires grassroots campuses and society to develop a series of effective measures and policies while introducing talents, and devote their work and study to the development of youth football. And by providing various forms of training and learning opportunities, the professional skills of football teachers and coaches can be continuously improved.

Last but not least, the development of football on campus is both necessary and feasible. The goal and task of education and teaching is to cultivate more outstanding, advanced and high-level talents, and more particularly, to strengthen the cultivation of highquality and high-level comprehensive talents. Although the creative spirit and practical ability are still relatively lacking, it is necessary to establish a connected campus football and professional football system, train excellent football students, encourage schools to introduce high-level coaches and retired athletes, and learn from the innovative spirit of professional football talents, which should arouse people's in-depth thoughts and suggestions.

\section{References}

[1] Wen Yanzhang, Qualitative Research on the Management Countermeasures and Evaluation System of Campus Football Characteristic Schools [A]. Summary of the 11th National Congress of Physical Education Science [C]. 2019. (in Chinese)

[2] Xu Yongjin, The Development of National School Football Characteristic Schools in Jiangsu Province: Current Situation, Problems and Countermeasures [A]. Summary of the 11th National Congress of Physical Education Science [C]. 2019. (in Chinese)

[3] Jin Xin, Innovative Discussion on Management Concept of Youth Football Training [J]. Ability and Wisdom, 2018(10). (in Chinese)

[4] Jia Chenglin, Yuan Yijie, Research on the Effectiveness of Junior Middle School Football Teaching [J]. Ability and Wisdom, 2013(06). (in Chinese)

[5] Zhou Guangyang, Research on Current Situation and Countermeasures of Campus Football Development in Primary and Middle Schools in Liaocheng [D]. Shaanxi Normal University, 2014. (in Chinese)

[6] Yue Yaopeng, Research on the Reform and Innovation of College Football Teaching under the New Course Standard [J]. Sports World Scholarly, 2018(03). (in Chinese)
[7] Sun Yi, Rao Gang, Li Chunlei, Liang Yongqiao, Lin Menglong, Japanese Campus Football: Development and Revelation [J]. Journal of Shanghai Physical Education Institute, 2017(01). (in Chinese)

[8] Qiu Lin, Dai Fuxiang, Zhang Ting'an, Zeng Dan, An Analysis of the Effect of Campus Football Policy Implementation in China and Its Main Affecting Factors [J]. Journal of Physical Education, 2016(06). (in Chinese)

[9] Li Zhuo, He Weili, Discussion on the Current Situation and Countermeasures of College Football Education [J]. Contemporary Sports Technology, 2017(35). (in Chinese)

[10] Yang Ling, Discussion on Football Teaching Reform in College Public Physical Education [J]. Sports World Scholarly, 2018(01). (in Chinese)

[11] Li Xuzhi, Research on the Innovation of the Management System of Youth Campus Football Activities in China [J]. New Curriculum: Elementary School, 2017(04). (in Chinese) 